\title{
ANÁLISE DA EFICIÊNCIA ENERGÉTICA DA FROTA DE VEÍCULOS LEVES NO
}

\section{BRASIL}

\author{
Rosiana da Silva Lopes ${ }^{1}$, Sergio Marcio Bicalho Silva ${ }^{2}$, Paulo César S. de Araújo e Fabrício \\ José Pacheco Pujatti ${ }^{1}$ \\ ${ }^{1}$ Universidade Federal de Minas Gerais - UFMG - Departamento de Engenharia Mecânica \\ ${ }^{2}$ Fiat Chrysler Automobiles - FCA Latam
}

E-mails: rosianalopes16@gmail.com, sergio.bicalho@fiat.com.br, paulo.araujo@fcagroup.com e pujatti@demec.ufmg.br

\section{RESUMO}

Este artigo apresenta uma análise da eficiência energética da frota brasileira de veículos leves nos últimos 8 anos. O setor de transporte rodoviário consome a maior parte dos combustíveis derivados do petróleo. O alto consumo de combustível gera problemas de poluição do ar e do meio ambiente. Com o proposito de preservar a qualidade do ar e dos recursos naturais o Governo Brasileiro criou programas que incentivam o aumento de eficiência energética veicular e redução das emissões de poluentes como o CONPET, o PROCONVE, o PBEV e INOVAR-AUTO. Este Artigo objetiva analisar a variação de eficiência energética da frota de veículos leves comercializados no Brasil nos últimos 8 anos. O trabalho foi realizado com consulta aos dados fornecidos pelo Programa Brasileiro de Etiquetagem Veicular (PBEV) no site do CONPET. Os resultados mostram que ocorreu aumento de eficiência energética com a redução de consumo energético médio da frota de $3 \%$ (de 2,27 para 2,20 MJ/km), mas a variação é bem maior considerando os veículos agrupados por categorias de acordo com suas características, pois a frota declarada sofreu alterações ao longo dos anos, os veículos Esportivos e Extra grandes tiveram consumo reduzido em $22 \%$, enquanto os veículos Compactos, Sub compactos e Micro compactos tiveram uma redução de $4 \%$. Com os resultados conclui-se que a frota brasileira teve um aumento de eficiência energética relativamente bom na última década devido os avanços tecnológicos desenvolvidos pela indústria automotiva.

\section{INTRODUÇÃO}

Nos dias atuais é praticamente inconcebível imaginar a sociedade sem os veículos automotivos. A popularidade destes utilitários se deve em parte ao aumento da população mundial e em parte ao avanço tecnológico que permitiu desenvolver veículos mais eficientes a custo acessível a grande parte da sociedade [1].

Os veículos são produtos que auxiliam as pessoas realizar suas atividades de maneira prática e confortável. A maioria dos veículos atuais é movida por motores de combustão interna que queimam combustíveis convertendo a energia química das ligações presentes no combustível em energia térmica e posteriormente em mecânica. Porém os principais combustíveis utilizados no mundo são de origem fóssil, a gasolina e óleo diesel, ambos derivados do 
petróleo. A combustão desses combustíveis lança para a atmosfera gases poluentes e tóxicos, o principal deles é o dióxido de carbono $\left(\mathrm{CO}_{2}\right)$ que não é tóxico, mas é um gás de efeito estufa (GEE). Os gases tóxicos são expelidos em menor proporção como o monóxido de carbono (CO), óxidos de nitrogênio (NOx), óxidos e Enxofre (SO2), material particulado no caso do óleo diesel e ainda hidrocarbonetos não queimados (THC) [2], [3] e [4].

As emissões de poluentes dos veículos automotivos provoca a deterioração da qualidade do ar e aumenta a poluição urbana, causando problemas de saúde às pessoas e animais. Em razão da quantidade de veículos usados no mundo a poluição e o consumo energético representa um sério problema. As emissões de dióxido de carbono dos veículos provoca o aumento da concentração de $\mathrm{CO}_{2}$ na atmosfera, pois o carbono dos combustíveis fósseis não é absorvido pela atmosfera, que consiste em um ciclo de carbono aberto, agravando o efeito estufa [3] e [5].

Com o objetivo de diminuir o consumo de combustíveis fósseis e as emissões veiculares, as autoridades de vários países têm adotado medidas e programas que incentivam, regulam e obrigam as indústrias automotivas a reduzirem seus níveis de emissões e aumentarem a eficiência energética de seus veículos. No Brasil os principais programas criados são: o Programa de Controle da Poluição do ar por Veículos automotivos (PROCONVE), o Programa Nacional de Racionalização do uso dos derivados do Petróleo e Gás Natural (CONPET), O Programa Brasileiro de Etiquetagem Veicular (PBEV) e Programa de Incentivo à Inovação Tecnológica e Adensamento da Cadeia Produtiva de Veículos Automotores (INOVAR-AUTO) [6] e [3].

Este artigo objetiva analisar a eficiência energética da frota de veículos leves no Brasil nos últimos oito anos.

\section{REVISÃO DA LITERATURA}

O setor de transporte é responsável pela maior parte do consumo de combustíveis derivados do petróleo, sendo o transporte rodoviário o maior consumidor. O uso elevado de veículos tem provocado aumento da poluição do ar por conta das emissões de $\mathrm{CO}_{2}$ e gases tóxicos. Em razão disso as emissões e o consumo energético veicular são alvos de políticas públicas e programas de incentivo à eficiência energética. Ao longo das últimas décadas o Governo adotou medidas para tentar reduzir os efeitos da elevada poluição e consumo de combustíveis fósseis pela frota veicular brasileira, exemplo de tais medidas foi a criação de programas com diferentes escopos, mas com um mesmo fim, de preservar os recursos naturais e promover a qualidade do meio ambiente para a geração atual e futuras. Os programas de maior relevância serão descritos a seguir [7], [4].

\subsection{Programa de Controle da Poluição do Ar por Veículos Automotivos (PROCONVE)}

O Conselho Nacional do Meio Ambiente (CONAMA) criou em 1986 o PROCONVE com o objetivo de reduzir os níveis de emissões de poluentes dos veículos automotivos e incentivar o desenvolvimento tecnológico automotivo [6].

O PROCONVE estabeleceu metas para as emissões de poluentes controlados (Hidrocarbonetos não metanos - NMHC, Monóxido de carbono - CO e Óxidos de nitrogênio - NOx), que foram aplicadas gradativamente, para que o setor automotivo 
conseguisse ao longo dos anos cumpri-las e assim, inserir no mercado veículos mais eficientes. O programa, que continua em vigência, também incentiva pesquisas no desenvolvimento de biocombustíveis, que é uma fonte de energia renovável. $\mathrm{O}$ PROCONVE foi organizado em fases, a cada fase os limites de emissões foram reduzidos, atualmente vigora a fase L6 para veículos leves (passeio) e a fase P7 para veículos pesados [2], [3] e [8].

1.2. Programa Nacional da Racionalização do uso dos derivados do petróleo e do gás natural (CONPET)

O CONPET foi criado em 1991 com a intenção de incentivar a conscientização para evitar desperdício de energia não renovável, o petróleo e gás natural. O CONPET trabalha em vários segmentos de energia como eletrodomésticos, mas uma das maiores atividades do CONPET diz respeito ao setor de transporte, que responde pelo maior consumo de combustíveis derivados do petróleo, sendo o transporte rodoviário correspondente a $90 \%$ do total de consumo do setor. O CONPET atua em parceria com o INMETRO na execução do Programa Brasileiro de Etiquetagem Veicular [7].

\subsection{Programa Brasileiro de Etiquetagem Veicular (PBEV)}

O Programa Brasileiro de Etiquetagem Veicular tem o propósito de incentivar o aumento da eficiência energética dos veículos por meio da divulgação dos índices de eficiência e emissões dos veículos em Etiquetas padronizadas fixadas nos veículos e também disponíveis no site do CONPET e do INMETRO. O programa é coordenado pelo INMETRO em parceria com o CONPET [9].

O PBEV contempla os veículos leves que utilizem gasolina e/ou etanol e diesel comercializados no Brasil, incluindo os importados. De acordo com as normas do Programa os veículos recebem a classificação de eficiência energética baseado em comparação dos resultados de ensaios de consumo veicular por Categoria de veículo e no Geral de $\mathbf{A}$ a $\mathbf{E}$, recebendo $\mathbf{A}$ os modelos mais eficientes e $\mathbf{E}$ os menos eficientes [9].

Apesar da adesão ao PBEV ser voluntária atualmente a maior parte da frota brasileira está inserida no programa. As empresas que aderiram ao PBEV devem fixar aos veículos a Etiqueta Nacional de Conservação de Energia para Veículos adotada pelo PBEV com as informações de consumo e emissões do veículo. O PBEV exigiu inicialmente que apenas uma parcela da frota de cada empresa fosse declarada e etiquetada, somente em 2017 as montadoras que participam do programa são obrigadas a declarar todos os veículos de suas frotas. O modelo da etiqueta de 2016 pode ser observado na Figura 1. As informações declaradas pelos fabricantes são detalhadas a seguir [7] e [9].

1. Classificação de emissões: indica o nível de emissões controladas, em relação ao limite estabelecido pelo PROCONVE, essa classificação varia de A a C, recebendo A os veículos que emitem menos poluentes (NMHC, NOx e CO). 
Figura 1: Etiqueta Nacional de Conservação de Energia de 2016. [9]

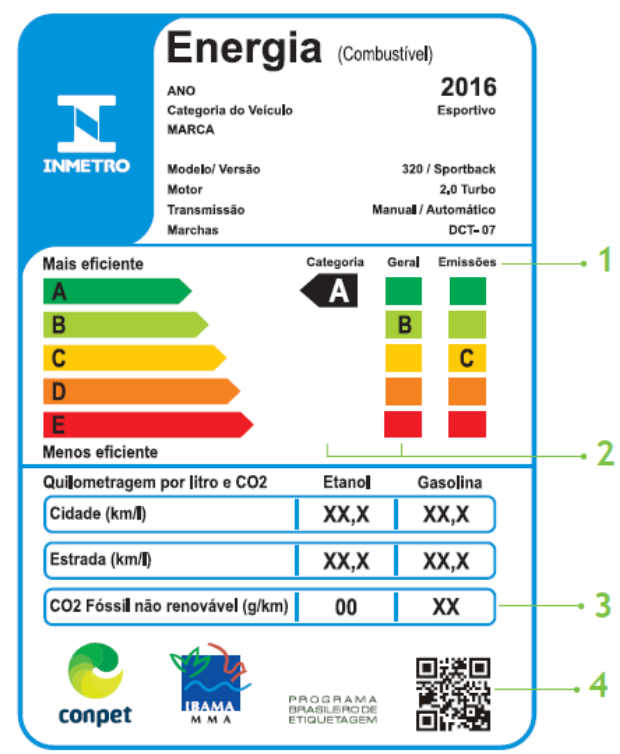

2. Classificação energética Categoria e Geral: indica a classificação de eficiência energética de acordo com o consumo de combustível da combinação do ciclo de condução urbano e estrada segundo as normas Brasileiras, a classificação varia de $\mathbf{A}$ a $\mathbf{E}$.

3. $\mathrm{CO}_{2}$ de origem fóssil: indica a quantidade de dióxido de carbono de origem fóssil é emitida pelo veículo.

4. Código QR: referência do aplicativo virtual de Etiquetagem Veicular para plataformas Android e IOS.

Acima das informações de $\mathrm{CO}_{2}$ de origem fóssil é declarada a autonomia dos veículos com o combustível Etanol e/ou Gasolina em km/litro. Além da Etiqueta o programa também concede o Selo CONPET aos veículos mais eficientes. Para receber o selo o veículo precisa receber classificação energética $\mathbf{A}$ no consumo por Categoria ou Geral e pelo menos B na outra. O Selo deve ser fixado no veículo ao lado da Etiqueta [9].

1.4. Programa de Incentivo à Inovação Tecnológica e Adensamento da Cadeia Produtiva de Veículos Automotores (INOVAR-AUTO).

O Programa de Incentivo à Inovação Tecnológica e Adensamento da Cadeia Produtiva de Veículos Automotores (INOVAR-AUTO) foi criado em 2012 no Brasil objetivando o desenvolvimento de tecnologias automotivas a fim de elevar a eficiência energética dos veículos. O Programa consiste em fornecer incentivos fiscais às empresas que invistam em desenvolvimento tecnológico e se comprometam a aumentar a eficiência energética de suas frotas [10].

O INOVAR-AUTO concedeu abatimento do IPI em $30 \%$ as montadoras que aderiram ao programa. Com base no mercado da época o Governo estabeleceu uma média do consumo energético da frota em 2012 levando em conta a massa média 
ponderada pelo volume de vendas para obter o valor de referência sob o qual deve ser aplicado o percentual de redução de consumo da frota de $12 \%$ até 2017 . Nesse cálculo o consumo médio ponderado em 2012 foi de 2,07 MJ/km para uma massa média de $1121 \mathrm{~kg}$, em 2017 o valor do consumo médio deve ser de no máximo 1,82 $\mathrm{MJ} / \mathrm{km}$ (considerando a massa de $1121 \mathrm{~kg}$ ). As montadoras que aderiram ao programa e não atenderem a meta devem pagar multas de alto valor ao governo. As empresas que porém conseguirem reduzir seu consumo abaixo de $1,75 \mathrm{MJ} / \mathrm{km}$ (15,46\% de redução) terão um bônus de abatimento de $1 \%$ do IPI e as que conseguirem abaixo de $1,68 \mathrm{MJ} / \mathrm{km}(18,84 \%$ de redução) terão $2 \%$ de IPI reduzido (considerando a massa média de $1121 \mathrm{~kg}$ ), para veículos com massas diferentes da referência o percentual de redução deve ser ajustado de acordo com a curva estabelecida pelo programa. A ponderação para esses cálculos é feita pelo volume de venda de cada modelo. Contudo o INOVAR-AUTO contempla apenas os veículos movidos a gasolina e/ou etanol, não abrange veículos movidos a diesel [11].

1.5. Medidas para redução do consumo de combustível e emissões veiculares

Para aumentar à eficiência dos veículos a indústria investiu e continua investindo em desenvolvimento de tecnologias para este fim, como é o caso do sistema Start Stop, que desliga o motor do veículo em períodos de parada em sinais de trânsito ou congestionamento, evitando o desperdício de combustível nesses períodos. A economia pode chegar a $20 \%$ (fora do ciclo de homologação) dependo do perfil de condução realizado e do tráfego [1].

Alguns veículos com câmbio manual já estão sendo equipados com um indicador de troca de marcha conhecido por GSI (do Inglês Gear Shift Indicator) que indica ao condutor o instante ideal para a troca de marcha, fazendo o veículo trabalhar na condição de melhor rendimento do motor, que consequentemente reduz o consumo de combustível [12].

Além destes itens outras medidas podem reduzir o consumo de combustível como a redução das forças de resistência ao deslocamento do veículo, como a resistência ao rolamento dos pneus e a resistência aerodinâmica. Os pneus dissipam energia devido à histerese do material que o constitui, a borracha. Para reduzir as perdas de energia com pneus foram desenvolvidos pneus conhecidos como pneus de baixa resistência ao rolamento, às vezes chamado de "pneus verdes" por serem mais econômicos. Estes pneus contém adição de componentes específicos, como a sílica, resultando em menores perdas de energia e menor consumo de combustível. Por outro lado a utilização de apêndices aerodinâmicos, e formas aerodinamicamente melhores também contribuem para um menor consumo de combustível, pois reduzem a resistência aerodinâmica [13] e [14].

Motores novos também foram desenvolvidos para melhorar a eficiência dos veículos, por exemplo os motores downsizing com 3 cilindros fabricados em alumínio. Novos câmbios e óleos sintéticos de baixo atritos são usados no motor e na caixa de transmissão reduzindo as perdas de energia por atrito [15] e [16]. 
A redução de consumo implica em redução das emissões de $\mathrm{CO}_{2}$ e de poluentes, mas outra forma de reduzir as emissões é por meio do tratamento dos gases de exaustão do motor com a utilização de conversores catalíticos [17].

Com os programas citados e a cobrança da sociedade, os fabricantes de veículos foram ao longo dos anos aprimorando suas frotas a fim de atender aos critérios cada vez mais exigentes. De forma que atualmente os veículos são mais econômicos e poluem menos do que algumas décadas atrás.

\section{METODOLOGIA}

Inicialmente foi realizado o levantamento bibliográfico dos programas criados no Brasil que objetivam aumento de eficiência energética e redução de emissões veiculares. Posteriormente foram realizadas consultas ao site do Conpet (endereço eletrônica: http://pbeveicular.petrobras.com.br/TabelaConsumo.aspx), com o qual foi possível obter os dados informados pelas empresas fabricantes de veículos que aderiram ao Programa Brasileiro de Etiquetagem Veicular para analisar as frotas declaradas nos últimos 8 anos. Foram obtidas as planilhas divulgadas pelo PBEV, respectivo ao período entre 2009 a 2016.

A análise de eficiência energética da frota foi realizada com o cálculo da média aritmética do consumo energético $(\mathrm{MJ} / \mathrm{km})$ declarado pelas fabricantes de veículos ao Programa Brasileiro de Etiquetagem Veicular em cada ano. Vale mencionar que o termo frota neste trabalho refere-se ao conjunto de veículos declarados no PBEV, sem considerar o volume de vendas de cada modelo. Também foram calculados os valores médios das emissões de poluentes controlados e de dióxido de carbono, além do percentual de veículos que possuem o selo CONPET.

Inicialmente os cálculos foram feitos considerando a frota uniformemente, gerando valores únicos para a frota de forma global. Entretanto foi observado que uma análise mais detalhada seria possível dividindo os veículos de acordo com as categorias a que eles pertencem. A fim de avaliar a variação de consumo dos veículos por categorias a frota subdividida em cinco grupos. Os veículos foram agrupados de acordo com sua categoria segundo a classificação do PBEV de acordo com a distribuição apresentada na Tabela 1.

Também foi calculado o percentual da frota por classificação energética (A, B, C, D e E) em cada ano.

Os dados declarados entre os anos de 2009 e 2012 fornecem menor quantidade de informações que no período entre 2013 a 2016, no primeiro período não foram divulgados os valores de emissões de poluentes controlados, $\mathrm{CO}_{2}$ e o consumo energético. Em razão disso para o período entre 2009 e 2012 a análise foi limitada a classificação de eficiência energética por categoria. Em relação ao período entre 2013 a 2016 foi analisada a redução de consumo energético médio, a classificação energética por categoria e emissões de $\mathrm{CO}_{2}$ e poluentes controlados.

Neste trabalho eficiência energética é considerada como a relação entre o consumo energético em um dado momento (2016) e o consumo energético de referência, que neste caso diz respeito ao ano de 2013. O tratamento dos dados e gráficos foi realizado no software Microsoft Excel® 2010. 
Tabela 1: Divisão das categorias de veículos segundo o PBEV

\begin{tabular}{|c|c|c|}
\hline Grupo & Nomeclatura adotada & Categorias segundo o PBEV \\
\hline \multirow{3}{*}{1} & \multirow{3}{*}{ Compactos } & Micro compacto \\
\hline & & Sub compacto \\
\hline & & Compacto \\
\hline \multirow{2}{*}{2} & \multirow{2}{*}{ Médios } & Médio \\
\hline & & Grande \\
\hline \multirow{4}{*}{3} & \multirow{4}{*}{ SUVs } & Utilitário esportivo compacto \\
\hline & & Utilitário esportivo grande \\
\hline & & Picape \\
\hline & & Fora de estrada \\
\hline \multirow{3}{*}{4} & \multirow{3}{*}{ Comerciais } & Comercial \\
\hline & & Minivan \\
\hline & & Carga derivado \\
\hline \multirow{2}{*}{5} & \multirow{2}{*}{ Outros } & Extra grande \\
\hline & & Esportivo \\
\hline
\end{tabular}

\section{RESULTADOS E DISCUSSÃO}

A Tabela 2 mostra a quantidade de modelos/versões declaradas em cada ano, a média das emissões de poluentes controlados, de $\mathrm{CO}_{2}$ de origem fóssil, do consumo energético e o percentual da frota que possui o selo CONPET.

Com Tabela 2 é possível observar inicialmente que a adesão ao PBEV foi gradativa e lenta, em 2016 foram declarados 1102 modelos/versões de veículos, enquanto em 2009 apenas 54 modelos/versões foram declaradas. Nota-se que as médias dos poluentes controlados (NMHC, CO e NOx) foram reduzidas a cada ano a partir de 2013, com exceção do NOx que aumentou no último ano. A redução de $\mathrm{CO}$ e NMHC provavelmente estão relacionadas ao aumento de eficiência na combustão dos motores e dos catalizadores. Também se observa uma leve redução de $\mathrm{CO}_{2}$ de origem fóssil.

Com relação ao consumo energético médio houve redução na média global da frota de 2,27 $\mathrm{MJ} / \mathrm{km}$ para 2,20 MJ/km, aproximadamente 3\% entre 2013 e 2016, este valor parece pouco expressivo levando em conta o investimento e desenvolvimento tecnológico alcançado nos últimos cinco anos por boa parte das empresas fabricantes de veículos no Brasil.

Porém, é importante destacar que no início do PBEV a adesão das empresas foi baixa e evidentemente é intuitivo pensar que as empresas que não participaram tinham veículos com consumo elevado. Outro ponto importante é que as empresas deviam declarar apenas uma parcela da frota, apenas a partir de 2017 as empresas que aderirem ao programa são obrigadas a declarar $100 \%$ de suas frotas, portanto é válido intuir que foram declarados os veículos mais eficientes nos primeiros anos e conforme o programa avançou a proporção das frotas de cada empresa também aumentou, promovendo a inserção dos veículos menos eficientes. Em outras palavras em 2013 os veículos declarados ao PBEV não representavam a totalidade da frota de veículos que foram comercializados naquele ano, mas apenas uma porção, que obviamente 
era a mais econômica. Se em 2013 tivessem sidos declarados todos os veículos ou equivalentes que foram em 2016 o consumo médio de 2013 provavelmente seria bem maior que $2,27 \mathrm{MJ} / \mathrm{km}$.

Tabela 2: Resultados da análise de eficiência energética e emissões da frota brasileira declarada no PBEV

\begin{tabular}{|c|c|c|c|c|c|c|c|}
\hline Ano & $\begin{array}{c}\text { Número de } \\
\text { Modelos da } \\
\text { frota } \\
\text { declarada }\end{array}$ & $\begin{array}{c}\text { NMHC } \\
{[\mathbf{g} / \mathbf{k m}]}\end{array}$ & $\begin{array}{c}\mathbf{C O} \\
{[\mathbf{g} / \mathbf{k m}]}\end{array}$ & $\begin{array}{c}\mathbf{N O x} \\
{[\mathbf{g} / \mathbf{k m}]}\end{array}$ & $\begin{array}{c}\text { CO2 } \\
\text { fóssil } \\
{[\mathbf{g} / \mathbf{k m}]}\end{array}$ & $\begin{array}{c}\text { Consumo } \\
\text { energético } \\
{[\mathbf{M J} / \mathbf{k m}]}\end{array}$ & $\begin{array}{c}\text { Selo } \\
\text { Conpet } \\
\mathbf{\%} \text { da } \\
\text { frota) }\end{array}$ \\
\hline 2009 & 54 & - & - & - & - & - & - \\
\hline 2010 & 62 & - & - & - & - & - & - \\
\hline 2011 & 83 & - & - & - & - & - & - \\
\hline 2012 & 205 & - & - & - & - & - & - \\
\hline 2013 & 448 & 0.027 & 0.395 & 0.035 & 138.86 & 2.27 & 25 \\
\hline 2014 & 599 & 0.024 & 0.365 & 0.031 & 138.97 & 2.26 & 29 \\
\hline 2015 & 693 & 0.021 & 0.33 & 0.023 & 138.13 & 2.25 & 24 \\
\hline 2016 & 1102 & 0.018 & 0.303 & 0.038 & 137.27 & 2.2 & 32 \\
\hline
\end{tabular}

Outro fator importante a se considerar sobre o consumo energético é que este está atrelado à massa do veículo, de forma que quanto maior seu peso maior é o consumo. De acordo com as planilhas do PBEV houve crescimento de veículos maiores, como os utilitários esportivos, picapes, fora de estrada, veículos comerciais entre outros no mercado brasileiro, que são veículos maiores e mais pesados. Portanto é esperado que inicialmente as empresas tenham declarado os veículos menores, mais leves, com consumo menor. Com o andamento do programa a frota declarada passou a representar melhor a frota real à medida que os veículos das demais categorias foram sendo inseridos no programa. Isso pode ser observado na Figura 2 .

Figura 2: Variação das categorias de veículos declarados no PBEV (\%)

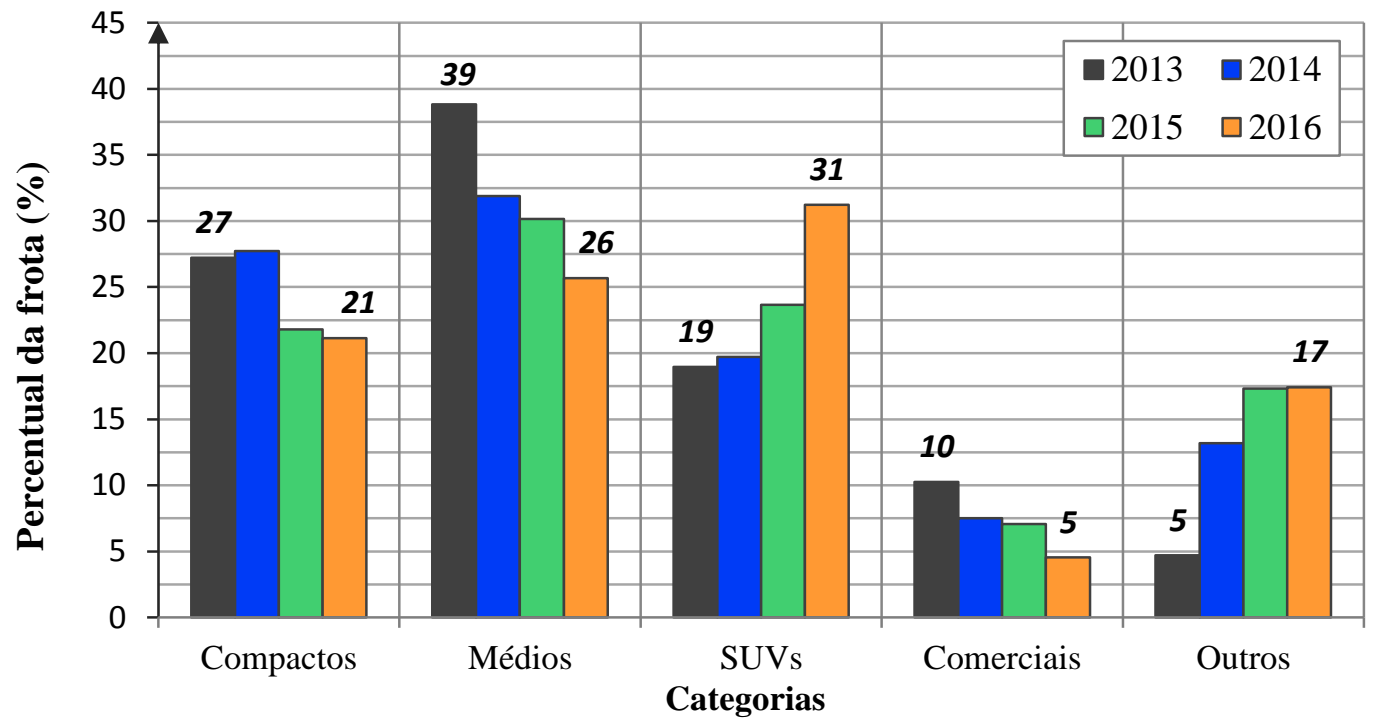


De acordo com a Figura 2 em 2013 a frota declarada no PBEV era composta majoritariamente por veículos compactos e médios, enquanto as demais categorias tinham pouca representatividade. Os Veículos SUVs e Outros apresentaram um crescimento considerável entre 2013 e 2016 . Ao comparar o consumo médio de forma global verifica-se apenas $3 \%$ de aumento de eficiência, contudo como houve redução do percentual de veículos menores (Compactos e Médios) que geralmente apresentam consumo menor que os veículos SUVs, Comerciais e Outros ao mesmo tempo em que ocorreu crescimento dos veículos SUVs e Outros, é interessante analisar o consumo médio por categorias de veículos, pois o peso dos veículos SUVs e Outros aumentou consideravelmente entre 2013 e 2016.

A Figura 3 apresenta a variação do consumo energético médio por categorias de veículos de 2013 e 2016 e a média global da frota calculada anteriormente.

Figura 3: Consumo energético médio por categorias e global de veículos declarados no PBEV

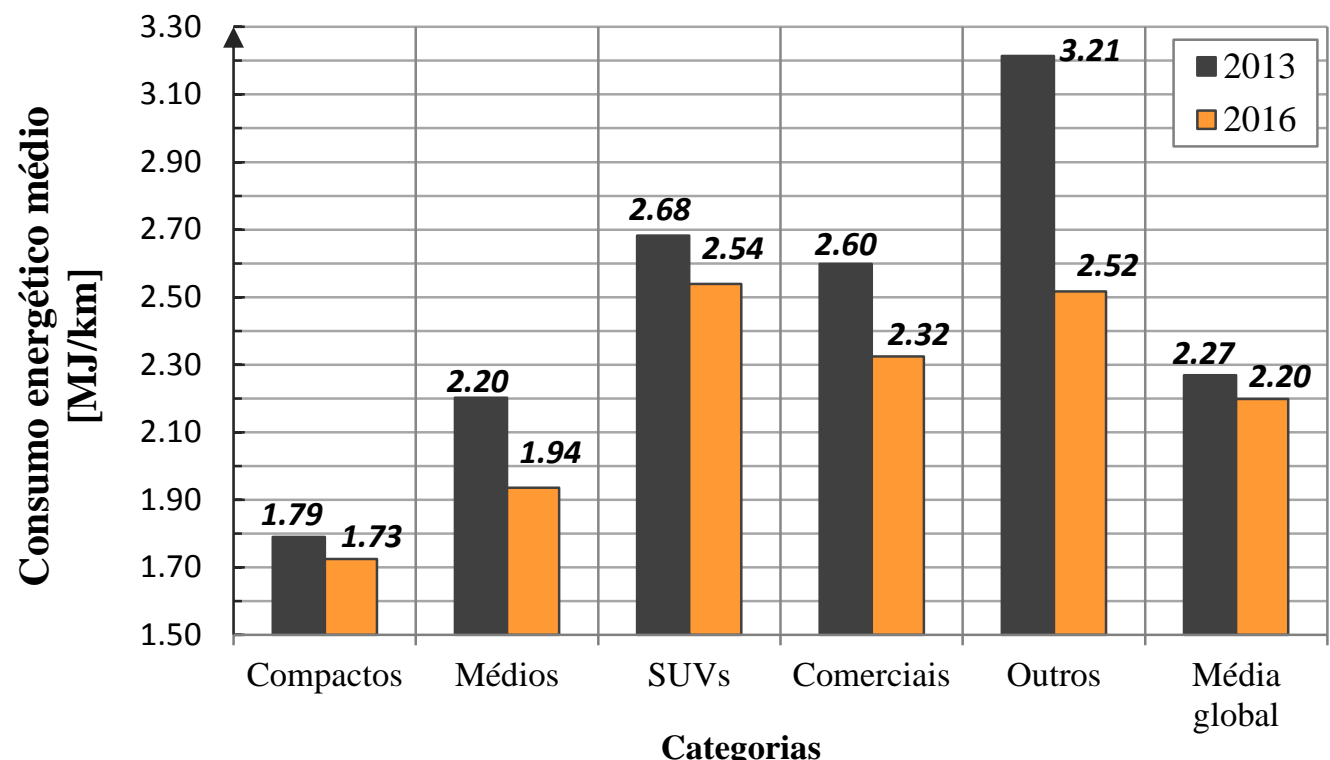

Como pode ser observado na Figura 3 o percentual de redução de consumo médio de todas as categorias de veículos foi maior que o obtido com a média global da frota (3\%). Os veículos Compactos (Micro compacto, Sub compactos e Compactos) tiveram redução de $4 \%$ no consumo energético, os médios (Médios e Grandes) 12\%, os SUVs (Utilitários esportivos compacto e grande, picape e fora de estrada) alcançaram $5 \%$ de redução, enquanto os Comerciais (Comercial, Minivans e Carga derivado) atingiram $11 \%$ e os Outros (Esportivos e Extra grandes) tiveram $22 \%$ de redução de consumo energético médio entre 2013 e 2016.

Os veículos compactos foram os que menos sofreram variações no consumo, isso se deve ao fato de que estes veículos já apresentavam consumo baixo em 2013, o que é coerente, pois o Programa de Etiquetagem começou em 2009 e em 2012 foi lançado o INOVAR-AUTO, que impulsionou o aumento de eficiência energética no Brasil, como os veículos compactos geralmente consomem menos, é válido supor que estes foram os primeiros veículos que as fabricantes trabalharam para melhorar a eficiência, levando a intuir que em 2013 os veículos compactos já apresentavam melhores resultados que em 2009, mas como o consumo energético não era declarado em 2009 não é possível comparar os dois períodos. Pelo Gráfico, Figura 3, pode-se perceber que houve melhorias nestes veículos, mas como em 2013 esses veículos já tinham consumo bom, a variação em relação à 2016 foi pequena. 
Nos demais grupos de veículos as variações de consumo foram maiores, mostrando que houve um trabalho grande das fabricantes para reduzir o consumo de todas as suas frotas, como pode ser observado o resultado mais expressivo foi dos veículos agrupados grupo Outros (Extra grande e Esportivo), seguido pelos veículos Médios (Médios e Grandes), Comerciais (Comercial, Minivan e Carga derivado) e pelos SUVs (Utilitários esportivos compactos e grandes, picapes e fora de estrada).

Para entender um pouco mais sobre o consumo energético é apresentado na Tabela 2 o consumo entre 2013 e 2016 por faixas de consumo, também é apresentado o polígono de frequência construído com o histograma dos dados de 2013 e 2016 na Figura 4.

Tabela 3: Consumo energético da frota por faixar de consumo (\% da frota)

\begin{tabular}{|c|c|c|c|c|c|}
\hline \multicolumn{2}{|c|}{$\begin{array}{c}\text { Faixas de consumo } \\
{[\mathrm{MJ} / \mathrm{km}]}\end{array}$} & \multirow{2}{*}{$\begin{array}{c}2013 \\
1\end{array}$} & \multirow{2}{*}{$\begin{array}{c}2014 \\
1\end{array}$} & \multirow{2}{*}{$\begin{array}{c}2015 \\
2\end{array}$} & \multirow{2}{*}{$\begin{array}{c}2016 \\
3 \\
\end{array}$} \\
\hline 1.25 & 1.50 & & & & \\
\hline 1.50 & -1.75 & 18 & 21 & 18 & 19 \\
\hline 1.75 & 2.00 & 25 & 24 & 22 & 23 \\
\hline 2.00 & -2.25 & 16 & 15 & 18 & 19 \\
\hline 2.25 & -2.50 & 12 & 12 & 17 & 11 \\
\hline 2.50 & -2.75 & 8 & 5 & 7 & 8 \\
\hline 2.75 & -3.00 & 4 & 10 & 7 & 9 \\
\hline 3.00 & -3.25 & 8 & 4 & 4 & 4 \\
\hline 3.25 & -3.50 & 3 & 3 & 3 & 2 \\
\hline 3.50 & $\begin{array}{l}-3.75 \\
\end{array}$ & 4 & 2 & 1 & 1 \\
\hline 3.75 & -4.00 & 0 & 2 & 2 & 1 \\
\hline \multicolumn{2}{|c|}{ Soma } & 99 & 99 & 100 & 99 \\
\hline
\end{tabular}

Figura 4: Polígono de frequência de consumo energético médio da frota de veículos

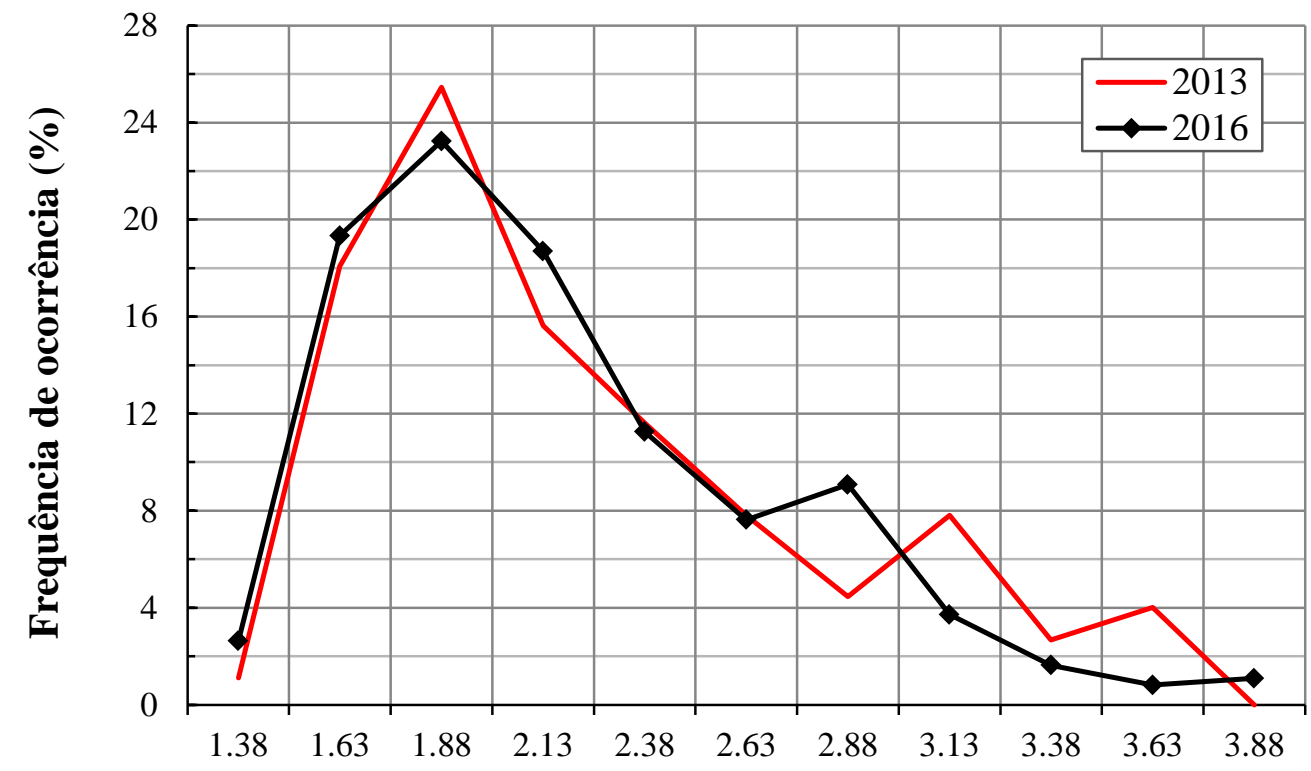

Consumo energético $(\mathrm{MJ} / \mathrm{km})$ 
A Tabela 3 e o polígono de frequência de consumo, Figura 4, permitem perceber que houve um pequeno aumento da proporção da frota que tem o consumo na faixa entre 1,25 e 1,75 $\mathrm{MJ} / \mathrm{km}$ e redução dos veículos inclusos na faixa entre 1,75 e 2,00 MJ/km, uma hipótese para esse resultado é que uma parcela dos veículos que se encaixavam na faixa de 1,75 e 2,00 $\mathrm{MJ} / \mathrm{km}$ teve seu consumo reduzido abaixo de $1,75 \mathrm{MJ} / \mathrm{km}$. A faixa de consumo entre 2,00 e $2,25 \mathrm{MJ} / \mathrm{km}$ teve um leve aumento, enquanto entre 2,25 a 2,75 MJ/km não houve alterações significativas, entre 2,75 e 3,00 MJ/km ocorreu um crescimento do percentual de veículos da frota e acima de 3,00 MJ/km praticamente só ocorreu redução do percentual da frota. De forma geral, houve mais crescimento das faixas de menor consumo e maior decréscimo das faixas de maior consumo, evidenciando a melhora dos veículos no que diz respeito a consumo energético. Porém novamente as variações são sutis devido à variação de categorias dentro da frota em cada ano como já mencionado. Em razão disso é apresentada nas Figuras de 5 a 9 os polígonos de frequência de consumo de cada categoria considerada neste trabalho.

Figura 5: Polígono de frequência de consumo energético - Compactos

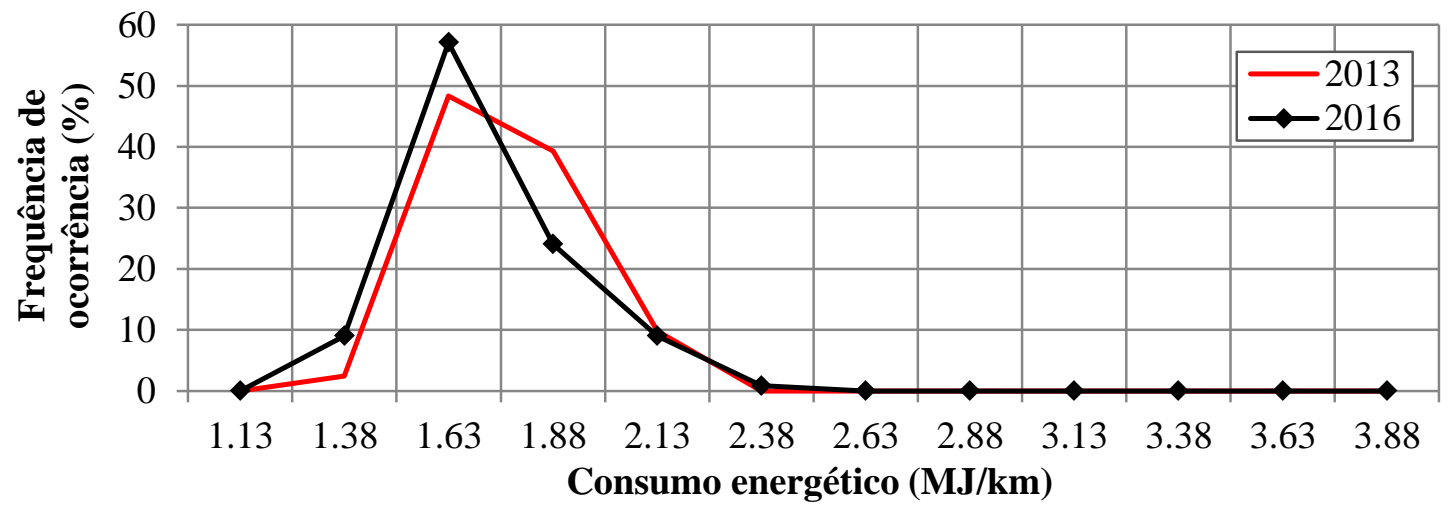

Figura 6: Polígono de frequência de consumo energético - Médios

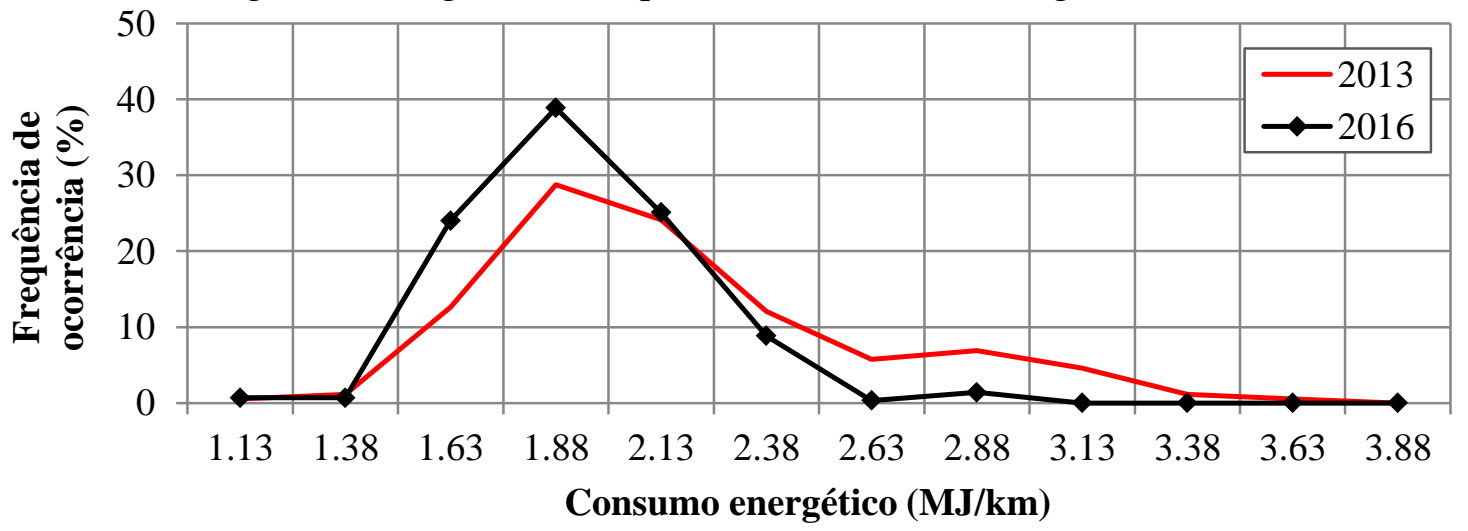

Em todos os Gráficos por categoria, Figuras 5 a 9, houve redução da frequência das faixas de maior consumo e aumento das faixas de menor consumo, que pode ser observado com o deslocamento dos picos para a esquerda. A curva dos veículos compactos, Figura 5, sofreu pequenas alterações, pois como dito anteriormente e o gráfico confirma que o consumo deste grupo de veículos já era baixo em 2013, a maior parte estava na faixa entre 1,50 e 2,00 $\mathrm{MJ} / \mathrm{km}$, ainda assim é observada uma melhora no consumo, a curva dos veículos médios teve maior variação que os compactos conforme pode ser observado na Figura 6. Enquanto as curvas dos demais veículos SUVs, Comerciais e Outros sofreram grandes variações 
confirmando que houve um trabalho intenso das empresas para melhorar esses veículos nos últimos anos e que este trabalho obteve bons resultados, logicamente o nível de consumo desses veículos é naturalmente mais elevado que os veículos compactos devido as suas características e finalidades de utilização, mas o aumento de eficiência foi realmente expressivo.

Figura 7: Polígono de frequência de consumo energético - SUVs

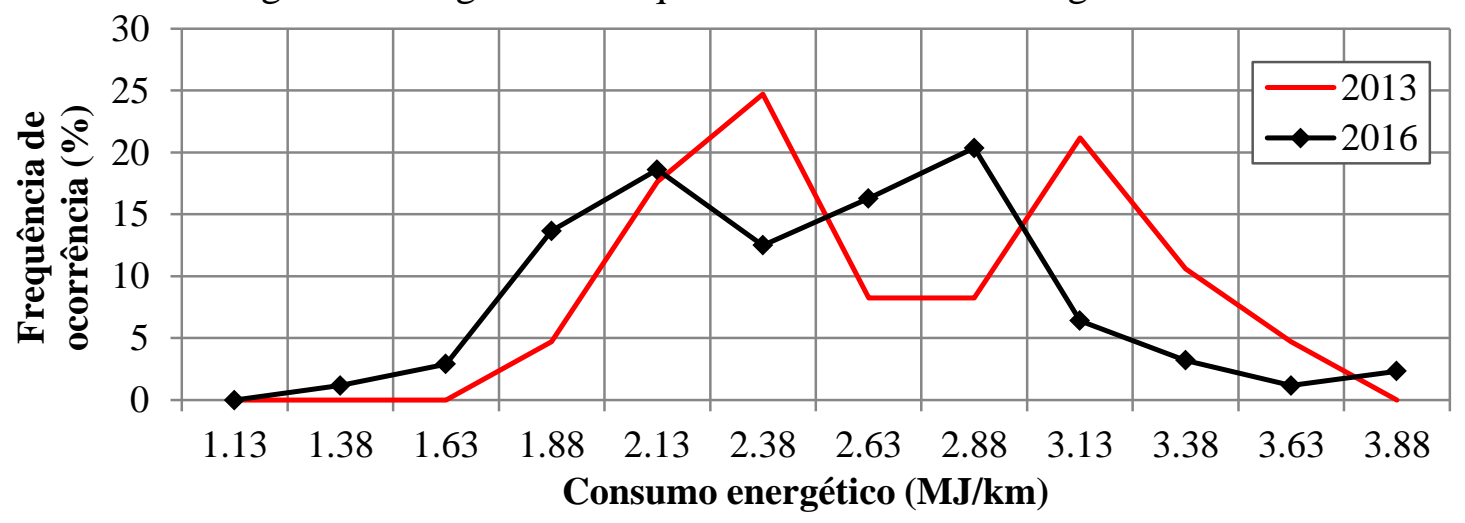

Figura 8: Polígono de frequência de consumo energético - Comerciais

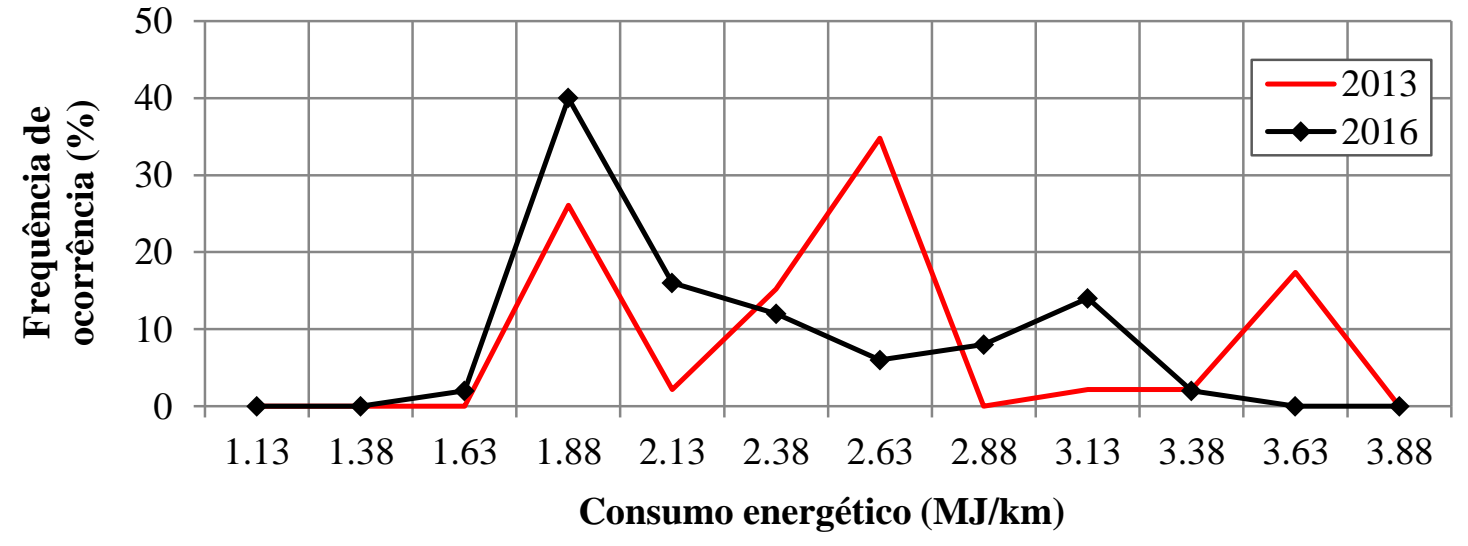

Figura 9: Polígono de frequência de consumo energético - Outros

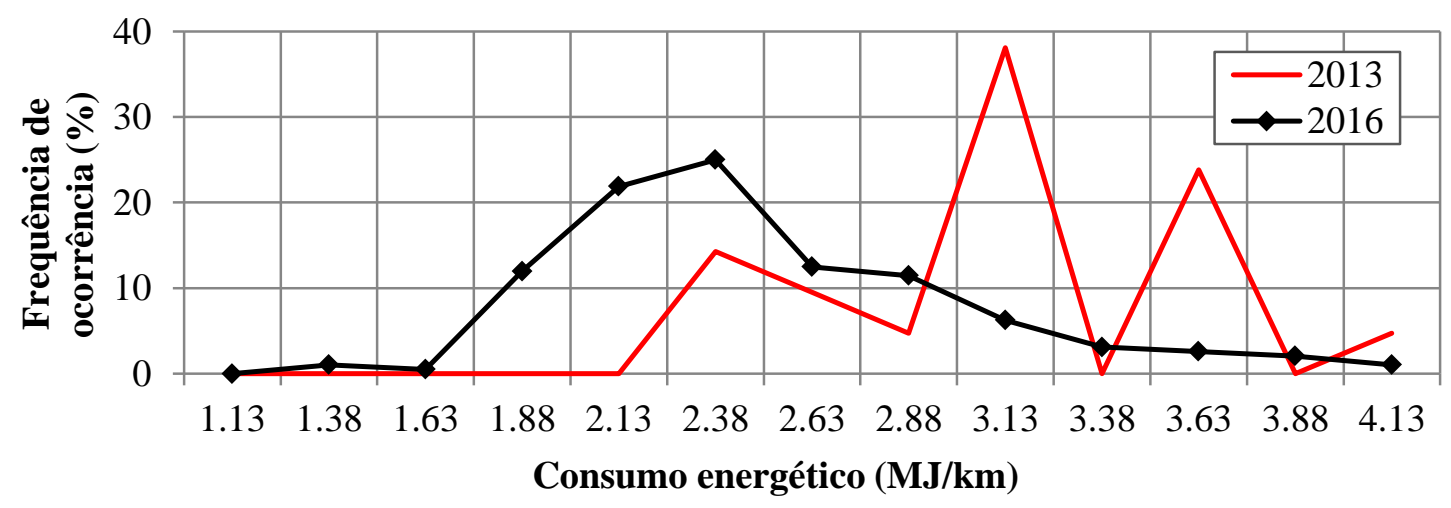

A Figura 10 mostra o histograma do percentual da frota segundo a classificação energética feita pelo PBEV por Categoria entre 2009 e 2016. 
Figura 10: Histograma da classificação energética por categoria da frota declarada no PBEV

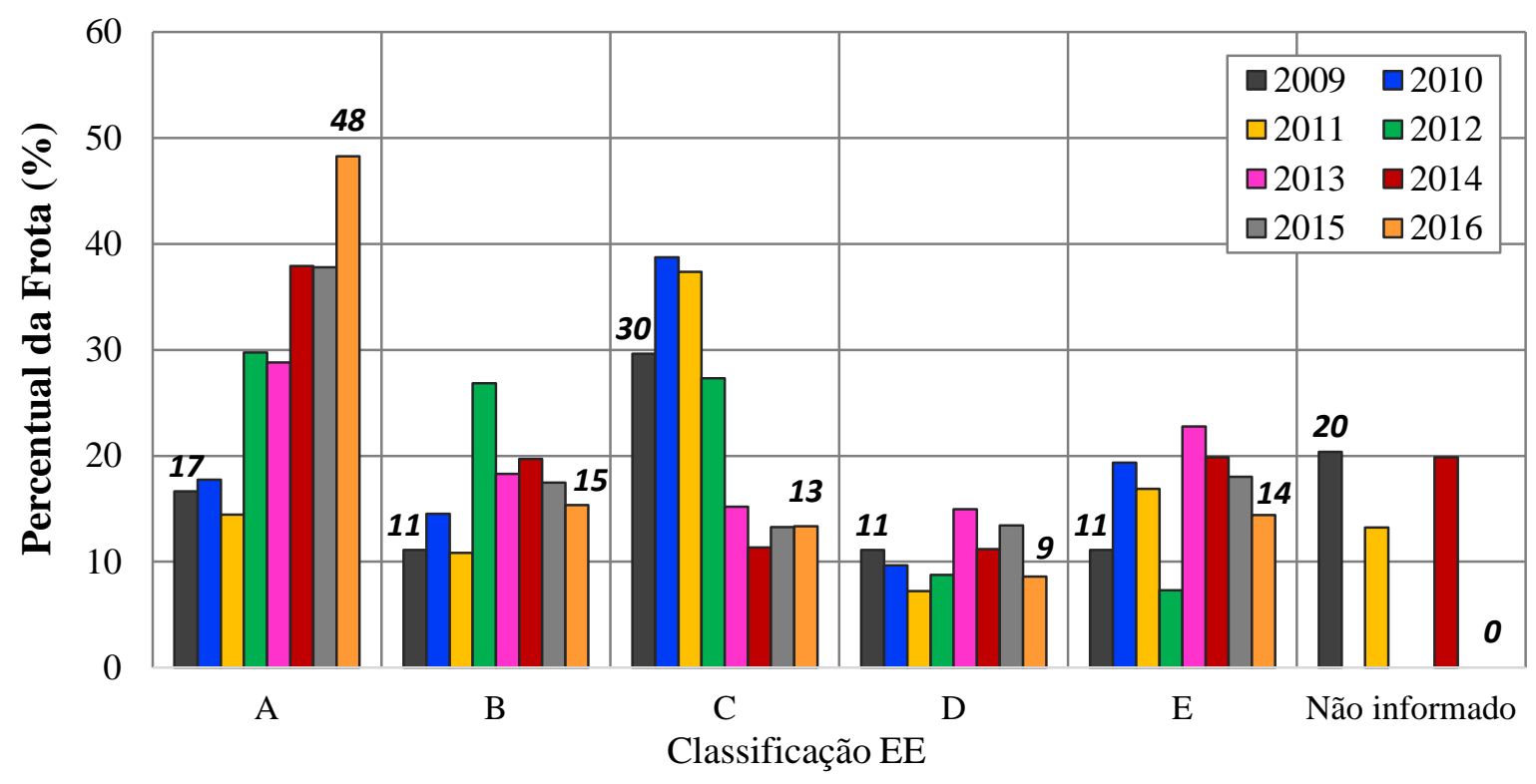

De acordo com a Figura 10 o percentual da frota com classificação energética $\mathbf{A}$ sofreu um aumento significativo de $17 \%$ em 2009 para 48\% em 2016, a segunda maior variação foi da classe $\mathbf{C}$ que caiu de $30 \%$ para $11 \%$ da frota, as demais classes não apresentaram grandes variações. Embora esta informação seja qualitativa, pois informa apenas variação da quantidade de veículos com cada classificação energética e não o quanto o consumo energético variou entre 2009 e 2016, é possível perceber um aumento de eficiência na frota de forma geral. É válido citar que os valores de referência para classificar os veículos são os mesmos desde sua criação, não houve por parte do programa alterações dos níveis de consumo para limitar as classes.

Por fim destaca-se que em 2017 100\% da frota das empresas deve ser declarada, de forma que nos próximos anos poderá ser realizada uma análise mais robusta da frota brasileira de veículos leves. Mas pelo conteúdo exposto pode-se afirmar que houve considerável avanço tecnológico automotivo nos últimos anos que promoveu aumento da eficiência energética da frota brasileira.

Também se destaca que todas as iniciativas tomadas para promover o desenvolvimento tecnológico automotivo no Brasil como os Programas Governamentais (PROCONVE, CONPET, PBEV e INOVAR-AUTO) foram e continuam sendo importantes para atingir os resultados observados. Dentre eles o PBEV se destaca como uma ferramenta que pode ser usada pelo consumidor para intervir no processo produtivo, pois permite escolher os veículos mais eficientes e cobrar das empresas veículos melhores para se tornarem competitivos, além do fato de uma vez declarados os valores é mais fácil monitorar seu consumo.

\section{CONCLUSÃO}

Este artigo apresentou uma análise da eficiência energética da frota de veículos leves no Brasil nos últimos 8 anos com base nos valores declarados pelas empresas ao Programa 
Brasileiro de Etiquetagem Veicular disponíveis no site do CONPET, atendendo o objetivo proposto. Com os resultados conclui-se que:

1. De forma qualitativa com os dados do PBEV é possível concluir que a frota brasileira teve aumento de eficiência energética entre 2009 e 2016 com o aumento da quantidade de veículos com classificação energética A de $17 \%$ para $48 \%$.

2. Quantitativamente o consumo energético médio da frota brasileira declarada no PBEV foi reduzido entre 2013 e 2016 em torno de 3\% de 2,27 MJ para 2,20 MJ/km considerando a média global da frota, mas este valor é bem maior quando se analisa os veículos divididos por categorias. Os veículos Esportivos e Extra grandes apresentaram 22\% de redução do consumo, os veículos Médios e Grandes reduziram $12 \%$, enquanto Comerciais, Minivans e Carga derivados tiveram $11 \%$ de redução no consumo, os Utilitários Esportivos Compactos e Grandes, Picapes e Fora de estrada tiveram seu consumo reduzido em $5 \%$ e os veículos Compactos, Sub compactos e Micro compactos 4\%. Estes resultados mostram que a heterogeneidade de veículos e as diferentes proporções de cada categoria declarada em cada ano devem ser consideradas em uma análise de eficiência energética da frota e não apenas um valor médio calculado com todos os veículos.

3. Com os resultados da análise de consumo energético foi observado uma redução expressiva do consumo energéticos dos veículos com pior consumo em 2013, como Esportivos, Extra grande, Comerciais, Minivans, SUVs, Carga derivado, Picapes, Fora de estrada, enquanto os veículos Compactos, Sub compactos e Micro compactos tiveram menores resultados, pois em 2013 estes veículos já era considerados bons no consumo energético e como apenas uma porção da frota devia ser declarada, estes veículos foram os primeiros a serem inseridos PBEV;

Para Trabalhos futuros propõe-se fazer análises dos dados declarados a partir de 2017, quando passa a ser obrigatória a declaração de $100 \%$ da frota das montadoras que participam do programa.

\section{AGRADECIMENTOS}

Os autores agradecem à Fiat Chrysler Automobiles - FCA pelo apoio financeiro e por incentivar o desenvolvimento tecnológico automotivo no Brasil por meio do PROGRAMA INOVAR FCA - UNIVERSIDADES - RESIDÊNCIA TECNOLÓGICA PARA ENGENHEIROS.

\section{REFERÊNCIAS}

[1] MARQUES, Carlos Filipe de Freitas. Estudo e análise do sistema de arranque e paragem automática do motor no automóvel. Porto: Dissertação de mestrado em Engenharia mecânica da Universidade de Porto, 2009.

[2] VICENTI, Pedro Caffaro. Uso de modelos de qualidade do ar para a avaliação do efeito do PROCONVE entre 2008 e 2010 na região metropolitana do Rio de Janeiro. Rio de Janeiro: Tese de Doutorado em Engenharia Mecânica da Universidade Federal do Rio de Janeiro, 2011. 
[3] MENDES, Francisco Eduardo. Avaliação de Programas de controle de poluição atmosférica por veículos leves no Brasil. Rio de Janeiro: Tese de Doutorado em Ciências em Planejamento energético da Universidade Federal do Rio de Janeiro, 2004.

[4] MMA, Ministério do Meio Ambiente. PROCONVE: PROGRAMA DE CONTROLE DE POLUIÇÃO DO AR POR VEÍCULOS AUTOMOTORES. Ministério do Meio Ambiente, 2011.

[5] GAZZONI, Décio Luiz. Balanço de emissões de CO2 por biocombustíveis no Brasil: histórico e perspectivas.EMBRAPA, 2012.

[6] CONAMA, Conselho Nacional do Meio Ambiente. Resolução. N. 18 de Maio de 1986. 1986.

[7] CONPET. Etiquetagem Veicular. Disponível em <http://www.conpet.gov.br/portal/c onpet/pt_br/conteudo-gerais/etiquetagem-veicular.shtml> acesso em 15/04/2017, 2012.

[8] MMA. Ministério do Meio Ambiente. Emissões Veiculares. Disponível em <http://www.mma.gov.br/mma-em-numeros/emissoes-veiculares> acesso em 30/01/2017 às $21: 17,2017$.

[9] CONPET. Programa Brasileiro de Etiquetagem Veicular. Disponível em <http://www.conpet.gov.br/portal/conpet/pt_br/pagina-inicial.shtml> acesso em 27/04/2017 às 10:29, 2016.

[10]. BRASIL. Lei n. ${ }^{\circ}$ 12.715, de 7 de setembro de 2012 - Institui o Programa de Incentivo à Inovação Tecnológica e Adensamento da Cadeia Produtiva de Veículos Automotores. 2012.

[11] INMETRO, Eficiência energética veicular: Políticas governamentais, Seminário Auto data Eficiência Energética, 2012.

[12] RENAULT. A vida está pedindo mais tecnologia. Disponível em <https://www.renault.com.br/veiculos/conheca-nossa-gama/duster-oroch/tecnologia.html> acesso em 07/05/2017, 2017.

[13] RHODIA. Sílica de alto desempenho para pneus verdes é tema principal de palestras técnicas da Rhodia. Expobor e Pneu Show 2016, 2016.

[14] CARDOSO, Fernando Aleixo. Estudo do desempenho dos compostos de borracha utilizados na fabricação da banda de rodagem dos pneus automotivos em função dos pavimentos das rodovias. São Paulo: Dissertação de mestrado em Engenharia Mecânica da Universdiade de São Paulo, 2010.

[15] VIDAL, Marlos Ney. Economia de combustível vai muito além da evolução do motor. Site Autos Segredo. $\quad$ Disponível em $<$ http://www.autossegredos.com.br/mercado/materias-especiais/economia-de-combustivelvai-muito-alem-da-evolucao-do-motor/>, em 22/03/2017 às 10:23, 2017.

[16] Fiat. Uno 2017. Site Fiat, Disponível em <http://www.fiat.com.br/carros/uno.html> acesso em 04/04/2017 às 09:58, 2017.

[17] INMETRO. Instituto Nacional de Metrologia, Normalização e Qualidade Industrial. Programa de análise de produto. Relatório sobre análise em conversor catalítico. Rio de Janeiro, 2007. 